\title{
Neonatal Asphyxia in Rats: Acute Effects on Cerebral Kynurenine Metabolism
}

\author{
GIANPIERA CERESOLI-BORRONI AND ROBERT SCHWARCZ \\ Maryland Psychiatric Research Center, University of Maryland School of Medicine, \\ Baltimore, Maryland, U.S.A.
}

\begin{abstract}
Two tryptophan metabolites, the anti-excitotoxic N-methylD-aspartate (NMDA) receptor antagonist kynurenic acid (KYNA) and the free radical generator 3-hydroxykynurenine (3-HK), have been proposed to influence neuronal viability in the mammalian brain. In rats, the brain content of both KYNA and 3-HK decreases immediately after birth, possibly to ensure normal postnatal functioning of NMDA receptors. Because complications of birth asphyxia have been suggested to be associated with anomalous NMDA receptor function, we examined the acute effects of an asphyctic insult on the brain levels of KYNA and 3-HK in neonatal rats. Asphyxia was induced in animals delivered by cesarean section on the last day of gestation, using the procedure introduced by Bjelke et al. (Brain Res 543: 1-9, 1991). KYNA and 3-HK levels were determined in the brain at seven time points between $10 \mathrm{~min}$ and $24 \mathrm{~h}$ after asphyxia. Up to
\end{abstract}

\section{ABSTRACT}

6 h, asphyxia caused $160-267 \%$ increases in KYNA levels. In the same tissues, 3-HK levels decreased (significantly at five of the seven time points), demonstrating an asphyxia-induced shift in kynurenine pathway metabolism toward the neuroprotectant KYNA. This shift might constitute the brain's attempt to counter the ill effects of birth asphyxia. Furthermore, the transient increase in the brain KYNA/3-HK ratio in these animals might be causally related to the well-documented detrimental long-term effects of asphyxia. (Pediatr Res 50: 231-235, 2001)

\author{
3-HK, 3-hydroxykynurenine \\ KYNA, kynurenic acid \\ NMDA, $N$-methyl-D-aspartate
}

Abbreviation
In newborn humans, birth asphyxia often causes rapid alterations in brain structure and function, which are in turn responsible for the development of cerebral palsy, mental retardation, and other catastrophic chronic conditions (1-4). These acute changes, and the subsequent evolution of permanent brain dysfunction, have been examined in numerous investigations using both invasive and noninvasive methods (cf. ref. 5-7 for review). These studies were complemented by preclinical work in experimental animal models, which allow superior scrutiny of asphyxia-induced behavioral, cellular, and molecular abnormalities and provide opportunities to test therapeutic interventions $(8,9)$.

An increasingly popular rat model of relatively mild birth asphyxia involves delivery of the uterine horn by cesarean section on the final day of gestation and the subsequent submersion of the uterus in $37^{\circ} \mathrm{C}$ water for $15-20 \mathrm{~min}$ (10). Thus, animals undergoing birth asphyxia have been shown to present with characteristic biochemical changes in the brain in the

Received October 3, 2000; accepted March 22, 2001.

Correspondence: Robert Schwarcz, Ph.D., Maryland Psychiatric Research Center, P.O. Box 21247, Baltimore, MD 21228, U.S.A.; e-mail: rschwarc@umaryland.edu Supported, in part, by United States Public Health Service grant HD16596. short and long term (11-15) and with distinct behavioral abnormalities as adults $(10,16,17)$.

Because it can be reasonably assumed that most pathologic sequelae of birth asphyxia are triggered by brain changes that occur in the immediate aftermath (i.e. within hours) of the insult, and potential remedies are likely to be most effective during this initial period, many experimental studies have focused on early postasphyctic events. This work has revealed, for example, rapid changes in brain metabolism, cellular $\mathrm{pH}$, and tissue levels of neurotransmitters such as dopamine and glutamate $(11,18)$. The latter effects, together with indications of benefits of antiglutamatergic interventions (19), have led to the suggestion that hyperglutamatergic, and perhaps excitotoxic, mechanisms play a major role in asphyxia-related brain pathology $(20,21)$.

Glutamatergic neurotransmission in the brain is governed not only by a spectrum of ionotropic and metabotropic glutamate receptors (22) but also by a number of different endogenous receptor ligands. One of these, the tryptophan metabolite KYNA, is a receptor antagonist and has a particularly high affinity for the glycine coagonist site of the NMDA receptor (23). Notably, through their common metabolic precursor Lkynurenine, KYNA is also closely related to $3-\mathrm{HK}$, a free radical generator with proexcitotoxic properties (24-26). 
KYNA has pronounced neuroprotective properties as evidenced, for example, by its ability to reduce hypoxic damage in immature animals $(27,28)$.

In several mammalian species, the brain levels of KYNA are exceptionally high during late gestational stages and decrease precipitously at birth (29-31). In rats, the only species examined to date, there is also a rapid and substantial postnatal reduction in the brain concentration of 3-HK (31). We therefore speculated that KYNA, in particular, might provide protection against hyperglutamatergic (asphyctic, hypoxic) injuries during birth. This might involve rapid mobilization of brain KYNA in the face of an insult. In a first approach to address this hypothesis, we decided to examine the early effects of birth asphyxia on the cerebral tissue content of KYNA and 3 -HK in rats.

\section{METHODS}

Materials. KYNA and 3-HK were purchased from Sigma Chemical Co. (St. Louis, MO, U.S.A.). All other chemicals were of the highest commercially available purity.

Animals. Time-pregnant Sprague Dawley rats were purchased from Charles River Laboratories (Raleigh, NC, U.S.A.) and kept at a $12 \mathrm{~h} / 12 \mathrm{~h}$ light-dark cycle with free access to food and water. The study was approved by the Institutional Animal Care and Use Committee of the University of Maryland.

Birth asphyxia. Birth asphyxia was performed using a slight modification of the model introduced by Bjelke et al. (10). Time-pregnant rats on the last day of gestation (embryonic day 22, E22) were decapitated, and an abdominal incision was made to isolate both uterine horns (cesarean section). Subsequently, the two uterine horns were rapidly (in 10-15 s) separated by ligation. One uterine horn was then immediately submerged in a beaker filled with a $37^{\circ} \mathrm{C}$ saline solution. After 15 min of asphyxia, pups were removed from the uterus, and their umbilical cords were ligated (time 0). Animals delivered from the second uterine horn in an identical fashion served as controls. Tactile stimulation was used in all neonatal rats to facilitate respiration. After recovery at $37^{\circ} \mathrm{C}$ for up to $60 \mathrm{~min}$, all pups were placed with a surrogate mother. Survival was $84 \%(51 / 61)$ in the asphyctic group and $100 \%(76 / 76)$ in the control group.

Pups were killed by decapitation at various times up to $24 \mathrm{~h}$ after delivery. The forebrain was rapidly dissected out, frozen on dry ice, and stored at $-70^{\circ} \mathrm{C}$ until the day of the assay.

Behavioral assessments. After delivery, animals were observed for behavioral changes. Between $10 \mathrm{~min}$ and $2 \mathrm{~h}$, the following parameters were recorded as described $(13,14)$ : skin color (scored from 0 to 3 , with 3 indicating pink, i.e. normal, color), gasping, (scored by the presence or absence of mouth opening), vocalization (scored by the presence or absence of vocalization upon handling of the animal), muscle tone (rated on a scale from 0 to 3 , with 3 indicating a strong resistance of a hind limb when the limb was flexed), and spontaneous activity (scored from 0 to 4 , with 4 indicating intense movements and wriggling, 3 indicating movements of all body parts, 2 indicating movements of two body parts, and 1 indicating movement of front legs or hind legs, or head alone).
Determination of brain KYNA. Frozen brain tissue was thawed and sonicated $(1: 10 \mathrm{wt} / \mathrm{vol})$ in distilled water. Two hundred microliters of the tissue homogenate was acidified with $50 \mu \mathrm{L}$ of $6 \%$ perchloric acid and centrifuged at $13,000 \times$ $g$ for $10 \mathrm{~min}$. Then, $125 \mu \mathrm{L}$ of the resulting supernatant was diluted with mobile phase (1:1, vol/vol; see below), and 200 $\mu \mathrm{L}$ was injected onto a $3-\mu \mathrm{m} \mathrm{C}_{18}$ reverse-phase HPLC column $(80 \times 4.6 \mathrm{~mm}$, ESA, Chelmsford, MA, U.S.A. $)$ using an autoinjector. KYNA was eluted at $1 \mathrm{~mL} / \mathrm{min}$ with a mobile phase containing $0.2 \mathrm{M}$ zinc acetate and 3.5\% acetonitrile, titrated to $\mathrm{pH} 6.2$ with glacial acetic acid. KYNA was detected fluorometrically (excitation wavelength: $344 \mathrm{~nm}$; emission wavelength: $398 \mathrm{~nm}$ ) using a Perkin Elmer LC240 fluorescence detector (Perkin Elmer, Beaconsfield, UK) (32).

Determination of brain 3-HK. A 50- $\mu \mathrm{L}$ aliquot of the tissue homogenate used for KYNA determination was acidified with $12.5 \mu \mathrm{L}$ of $6 \%$ perchloric acid. Samples were kept on ice for $10 \mathrm{~min}$ before centrifugation $(10 \mathrm{~min}, 13,000 \times \mathrm{g})$. Then, 20 $\mu \mathrm{L}$ of the resulting supernatant was injected onto a $3-\mu \mathrm{m} \mathrm{C}_{18}$ reverse-phase HLPC column $(80 \times 4.6 \mathrm{~mm}$, ESA $)$ using a refrigerated autoinjector (ISS 200, Perkin Elmer). 3-HK was eluted isocratically at $20^{\circ} \mathrm{C}$ at $1 \mathrm{~mL} / \mathrm{min}$ using a mobile phase containing $2 \%$ acetonitrile, $0.9 \%$ triethylamine, $0.59 \%$ phosphoric acid, $0.27 \mathrm{mM}$ sodium EDTA, and $8.9 \mathrm{mM}$ heptane sulfonic acid. 3-HK was detected electrochemically (Coulochem 5100A, ESA) using an analytical cell with the oxidation voltage set at $+0.20 \mathrm{~V}(33)$.

Protein determination. The protein content of tissue homogenate was determined according to the method of Lowry et al. (34).

Data analysis. Behavioral responses were compared using $\chi^{2}$ tests for vocalization and gasping, and the Kruskal-Wallis (Wilcoxon rank) test for responses measured as ordered categories. Levels of KYNA and 3-HK were analyzed using twoway ANOVA with time and asphyxia as main effects, and tests for asphyxia by time interaction. Posthoc $t$-tests were performed comparing asphyctic and nonasphyctic rats at individual time points.

\section{RESULTS}

Behavioral observations. In agreement with the literature $(13,14)$, a 15-min episode of asphyxia had pronounced and immediate behavioral effects in neonatal rats. Several of the parameters listed in Table 1 correspond to the Apgar score used for newborn babies (7). At 10 min after birth, asphyctic pups had a pale skin color compared with the pink color of control animals. Moreover, asphyctic animals gasped for air, and seemed to vocalize less upon handling. At this early interval, the pups also did not show voluntary limb or body movements and had a flaccid tone. In contrast to the other acute behavioral effects of asphyxia, changes in skin color and vocalization did not attain statistical significance. Starting at $30 \mathrm{~min}$ and up to $2 \mathrm{~h}$ (the latest time point assessed for behavioral changes), differences between asphyctic and control animals became progressively less pronounced. Thus, at $30 \mathrm{~min}$, asphyctic animals had stopped gasping and vocalized normally upon handling but were still hypotonic and hypoactive. By $1 \mathrm{~h}$, 
muscle tone and spontaneous activity, too, had returned to control values (Table 1).

Effect of birth asphyxia on brain KYNA levels. Brain KYNA concentrations in control animals declined dramatically immediately after birth and gradually decreased further during the first $24 \mathrm{~h}$ of life (Fig. 1). A period of asphyxia resulted in a significantly higher level of brain KYNA compared with controls between $10 \mathrm{~min}$ and $6 \mathrm{~h}$, but not $24 \mathrm{~h}$ after the insult. The average increase over this period was $493 \pm 44$ fmoles $/ \mathrm{mg}$ protein $(F=128.2, d f=1,112, p<0.05)$, with no significant variation $(F=1.04, d f=5,107, p>0.05)$. By $24 \mathrm{~h}$, however, there was no elevation in KYNA levels in asphyctic animals compared with controls. At each of the six time points tested (\# $6 \mathrm{~h}$ ), KYNA levels in the asphyctic group were approximately 2-fold higher than in controls ( $p<0.05$, unpaired $t$ test).

Effect of birth asphyxia on brain 3-HK levels. In control animals, the brain content of 3-HK decreased postnatally, but a significant decline from embryonic levels was not observed until $6 \mathrm{~h}$ after birth (Fig. 2). In asphyctic animals, brain 3-HK levels tended to be lower than in controls. Overall, ANOVA revealed an average difference of $524 \pm 91$ fmoles $3-\mathrm{HK} / \mathrm{mg}$ protein between asphyctic animals and controls $(F=33.4, d f$ $=1,124, p<0.05)$, which did not vary significantly $(F=$ $1.56, d f=6,118, p>0.05)$ over the 24 -h period. At individual postnatal time points, the asphyxia-induced decrease reached statistical significance at $10 \mathrm{~min}, 60 \mathrm{~min}, 90 \mathrm{~min}, 2 \mathrm{~h}$, and $24 \mathrm{~h}$ ( $p<0.05$, unpaired $t$ test).

KYNA/3-HK ratio. Up to $24 \mathrm{~h}$ after delivery, the ratio between KYNA and 3-HK in the brain of asphyctic animals was between 1.9- and 3.7-fold higher than in controls. This increase reached statistical significance at all time points \# $6 \mathrm{~h}$ (Table 2).

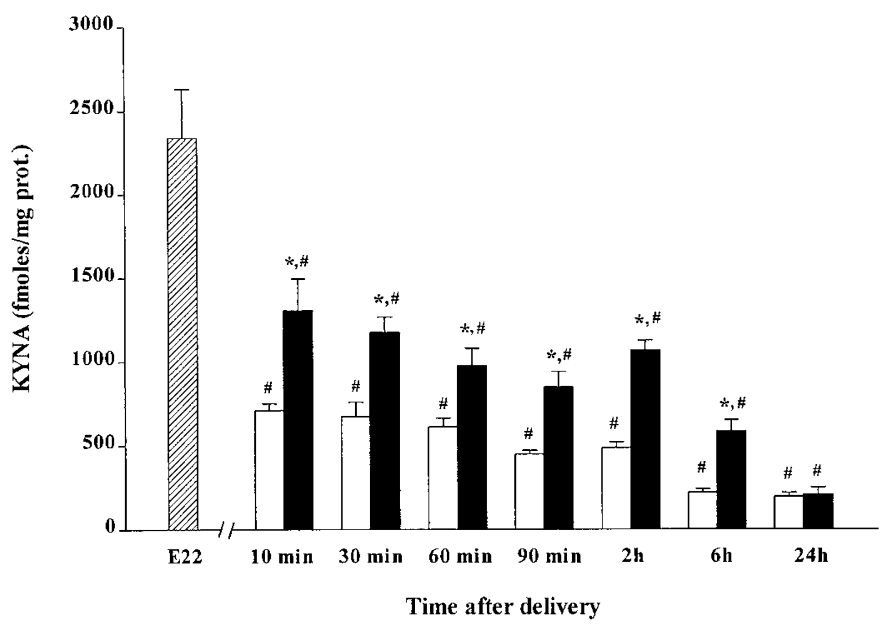

Figure 1. Brain KYNA levels in control $(\square)$ and asphyctic rats ( $\square$ ) at various time points after delivery. Data are the mean \pm SEM of 5-16 animals per postnatal time point. "E22" $(n=5)$ depicts the brain KYNA level in animals delivered by cesarean section on embryonic d 22 and killed immediately. Experiments were performed as described in the text. $* p<0.05$ vs controls, \#p<0.05 vs E22 (unpaired $t$ tests).

\section{DISCUSSION}

Using an established rat model in which relatively moderate asphyxia is caused by submerging the isolated uterus for 15 min at $37^{\circ} \mathrm{C}$ in a saline bath (10), the present study constituted an initial effort to determine the possible significance of the high KYNA and 3-HK concentrations that are seen in the embryonic brain of nonhuman primates, sheep, and rats (2931). The results demonstrated that birth asphyxia has opposite effects on the brain tissue content of KYNA and 3-HK during

Table 1. Behavioral observations at various times after delivery

\begin{tabular}{|c|c|c|c|c|c|}
\hline & $10 \mathrm{~min}$ & $30 \mathrm{~min}$ & $60 \mathrm{~min}$ & $90 \min$ & $2 \mathrm{~h}$ \\
\hline \multicolumn{6}{|l|}{ Skin } \\
\hline Control & $3.00 \pm 0.0$ & $3.00 \pm 0.0$ & $3.0 \pm 0.0$ & $3.00 \pm 0.0$ & $3.00 \pm 0.0$ \\
\hline Asphyxia & $2.87 \pm 0.07$ & $2.94 \pm 0.06$ & $3.00 \pm 0.0$ & $3.00 \pm 0.0$ & $3.00 \pm 0.0$ \\
\hline$p$ Value & 0.24 & $>0.99$ & $>0.99$ & $>0.99$ & $>0.99$ \\
\hline \multicolumn{6}{|l|}{ Gasping } \\
\hline Control & $0 / 22$ & $0 / 18$ & $0 / 14$ & $0 / 10$ & $0 / 6$ \\
\hline$p$ Value & $<0.001$ & $>0.99$ & $>0.99$ & $>0.99$ & $>0.99$ \\
\hline \multicolumn{6}{|l|}{ Vocalization } \\
\hline Control & $18 / 22$ & $18 / 18$ & $14 / 14$ & $10 / 10$ & $6 / 6$ \\
\hline Asphyxia & $16 / 24$ & $18 / 20$ & $16 / 16$ & $12 / 12$ & $8 / 8$ \\
\hline$\chi^{2}(d f=1)$ & 1.37 & 0.00 & 0.00 & 0.00 & 0.00 \\
\hline$p$ Value & 0.24 & $>0.99$ & $>0.99$ & $>0.99$ & $>0.99$ \\
\hline$p$ Value & $<0.001$ & $<0.001$ & 0.007 & 0.14 & $>0.99$ \\
\hline \multicolumn{6}{|c|}{ Spontaneous activity } \\
\hline Control & $1.91 \pm 0.11$ & $2.67 \pm 0.11$ & $3.43 \pm 0.14$ & $3.70 \pm 0.15$ & $3.50 \pm 0.22$ \\
\hline Asphyxia & $0.04 \pm 0.04$ & $1.25 \pm 0.19$ & $2.56 \pm 0.13$ & $3.58 \pm 0.15$ & $3.50 \pm 0.19$ \\
\hline$\chi^{2}(d f=1)$ & 39.15 & 21.61 & 12.50 & 0.31 & 0.70 \\
\hline$p$ Value & $<0.001$ & $<0.001$ & $<0.001$ & 0.67 & $>0.99$ \\
\hline
\end{tabular}

$p$ Values and chi-squares from Wilcoxon rank test for ordered categories or Pearson chi-squares for yes/no responses. All parameters were rated as described in the text, using 22 control and 24 asphyctic animals. Mortality in the asphyctic group was $4 \%(1 / 24)$. 


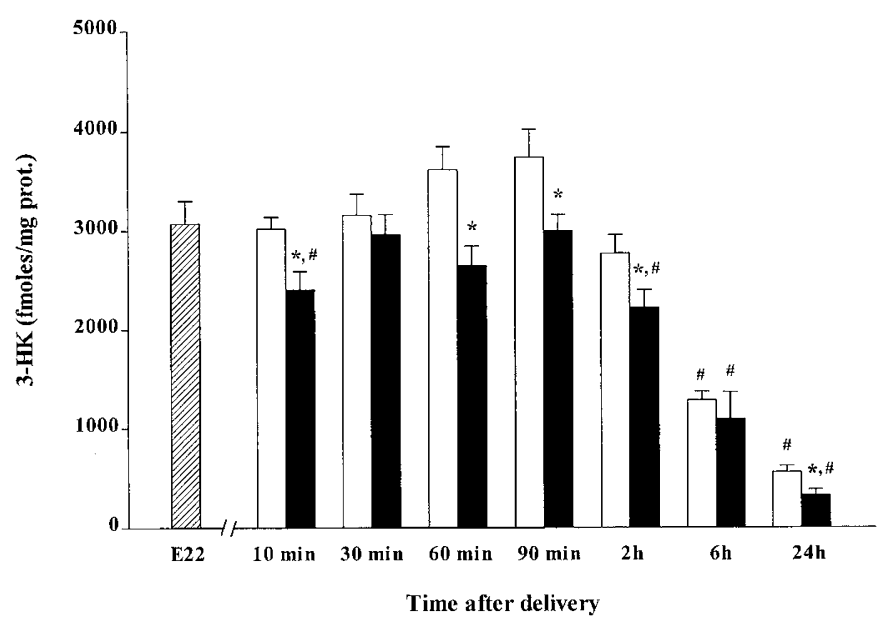

Figure 2. Brain 3-HK levels in control $(\square)$ and asphyctic rats ( $\square$ ) at various time points after delivery. Data are the mean \pm SEM of 5-16 animals per postnatal time point. "E22" ( $n=5)$ depicts the brain 3-HK level in animals delivered by cesarean section on embryonic d 22 and killed immediately. Experiments were performed as described in the text. ${ }^{*} p<0.05$ vs controls, $\# p$ $<0.05$ vs E22 (unpaired $t$ tests).

the first $24 \mathrm{~h}$ after the insult. Thus, asphyxia substantially attenuated the dramatic reduction in brain KYNA that is normally observed shortly after birth, but further advanced the postnatal decrease in brain 3-HK levels. Taken together, the experimental injury therefore led to acute, 2- to 3-fold increases in the KYNA/3-HK ratio in the brain.

KYNA and 3-HK are both primary degradation products of L-kynurenine and thus metabolites of competing branches of the kynurenine pathway of tryptophan catabolism (35). In adults, chronic changes in the brain concentrations of both compounds occur under several pathologic conditions, but abnormal levels of one metabolite are not necessarily accompanied by changes in the other. For example, the brain content of 3-HK and its downstream metabolites surge dramatically in immunocompromised humans and animals, probably due to infiltrating macrophages and the activation of microglia (36, 37). Because these cells contain only small amounts of kynurenine aminotransferases, the biosynthetic enzymes of KYNA that are preferentially localized in astrocytes $(38,39)$, KYNA levels in the same tissues increase only moderately (36). In contrast, cerebral kynurenine metabolism along both branches of the pathway is stimulated in chronically lesioned brain or spinal cord, probably because both astrocytes and microglia are abundant in neuron-depleted tissue (39-41).

Table 2. Brain $K Y N A / 3 H K$ ratio at various times after delivery

\begin{tabular}{lccc}
\hline & Control & Asphyxia & $\Delta(\%)$ \\
\hline $10 \mathrm{~min}$ & $0.24 \pm 0.02$ & $0.58 \pm 0.10^{*}$ & +242 \\
$30 \mathrm{~min}$ & $0.21 \pm 0.02$ & $0.40 \pm 0.02^{*}$ & +190 \\
$60 \mathrm{~min}$ & $0.17 \pm 0.01$ & $0.39 \pm 0.06^{*}$ & +229 \\
$90 \mathrm{~min}$ & $0.13 \pm 0.01$ & $0.29 \pm 0.04^{*}$ & +223 \\
$2 \mathrm{~h}$ & $0.19 \pm 0.02$ & $0.55 \pm 0.07^{*}$ & +289 \\
$6 \mathrm{~h}$ & $0.18 \pm 0.02$ & $0.66 \pm 0.18^{*}$ & +367 \\
$24 \mathrm{~h}$ & $0.34 \pm 0.05$ & $0.80 \pm 0.28$ & +235 \\
\hline
\end{tabular}

Data are the mean \pm SEM of 5-16 animals per time point.

$* p<0.05 v s$. controls (unpaired $t$ test).
An acute excitotoxic insult to the adult rat brain causes a rapid increase in the de novo synthesis of KYNA and a concomitant reduction in 3-HK formation (42). Moreover, KYNA levels in the brain rise substantially within $1-2 \mathrm{~h}$ after the induction of seizure activity $(43,44)$ or after a focal excitotoxin injection (39). These data suggest that a shift in kynurenine pathway metabolism, favoring the mobilization of the neuroprotectant KYNA and diminishing the formation of the toxin 3-HK (25), might constitute a common defense mechanism of the brain to acutely combat injuries. While the cellular and molecular mechanisms underlying this rapid metabolic shift toward an increased KYNA/3-HK ratio and enhanced KYNA availability are currently not understood, the present results indicate that they also operate in the neonatal brain. Because of the very high prenatal brain content of KYNA, however, the effect of birth asphyxia manifested itself as an attenuation of the precipitous postnatal decline rather than an absolute increase in KYNA levels.

NMDA receptor activation does not only play a central role in excitotoxicity (45) but is also critically involved in cognitive functions (46). In the immature brain, NMDA receptors are crucial for synapse development (47) and for the modulation of neuronal migration (48). Conceptually, the high content of the NMDA receptor antagonist KYNA in the embryonic brain might therefore provide an antiexcitotoxic (i.e. antihypoxic) defense during birth, whereas the swift decline in brain KYNA immediately after birth would assure minimal interference with developmentally essential postnatal NMDA receptor functions. Notably, fluctuations in the brain content of KYNA have indeed been demonstrated to influence NMDA receptor function (49-51), especially when combined with an opposite deflection of cerebral 3-HK levels (52). The present data therefore raise the question of the functional consequences of the asphyxia-induced, rapid increase in the cerebral KYNA/ 3-HK ratio. It is conceivable that this transient metabolic change, which is accompanied by an elevation in the levels of the neuroprotective neuronal fuel lactate $(11,53,54)$, augments endogenous neuroprotection but at the same time impedes normal NMDA receptor function in the neonate (55). Experiments to examine these possibilities, as well as the potential role of these early biochemical changes in the long-term effects of birth asphyxia $(6-8,10-16,19)$, are currently in progress in our laboratory.

Acknowledgments. The authors thank Mrs. Joyce Burgess for excellent secretarial assistance and Dr. R. McMahon for help with statistical analyses.

\section{REFERENCES}

1. Hagberg B, Hagberg G, Lewerth A, Lindberg U 1981 Mild mental retardation in Swedish school children. Acta Paediatr Scand 70:445-452

2. Perlman JM 1997 Intrapartum hypoxic-ischemic cerebral injury and subsequent cerebral palsy: medicolegal issues. Pediatrics 99:851-859

3. Rosso IM, Cannon TD, Huttunen T, Huttunen MO, Lönnqvist J, Gasperoni TL 2000 Obstetric risk factors for early-onset schizophrenia in a Finnish birth cohort. Am J Psychiatry 157:801-807

4. Nyakas C, Buwalda B, Luiten PGM 1996 Hypoxia and brain development. Prog Neurobiol 49:1-51

5. Volpe JJ 1995 Hypoxic-ischemic encephalopathy: clinical aspects. In: Neurology of the Newborn, 3rd Ed. WB Saunders, Philadelphia, pp 279-344 
6. Simon NP 1999 Long-term neurodevelopmental outcome of asphyxiated newborns. Clin Perinatol 26:767-778

7. Roland EH, Poskitt K, Rodriguez E, Lupton BA, Hill A 1998 Perinatal hypoxicischemic thalamic injury: clinical features and neuroimaging. Ann Neurol 44:161166

8. Loidl CF, Capani F, Lopez-Costa JJ, Selvin-Testa A, Lopez EM, Pecci-Saavedra J 1997 Long term changes in NADPH-diaphorase reactivity in striatal and cortical neurons following experimental perinatal asphyxia: neuroprotective effects of hypothermia. Int J Neurosci 89:1-14

9. Chen Y, Ögren S-O, Bjelke B, Bolme P, Eneroth P, Gross J, Loidl F, HerreraMarschitz M, Andersson K 1995 Nicotine treatment counteracts perinatal asphyxiainduced changes in the mesostriatal/limbic dopamine systems and in motor behaviour in the four-week-old male rat. Neuroscience 68:531-538

10. Bjelke B, Andersson K, Ögren SO, Bolme P 1991 Asphyctic lesion: proliferation of tyrosine hydroxylase-immunoreactive nerve cell bodies in the rat substantia nigra and functional changes in dopamine neurotransmission. Brain Res 543:1-9

11. Chen Y, Engidawork E, Loidl F, Dell'Anna E, Goiny M, Lubec G, Andersson K, Herrera-Marschitz M 1997 Short- and long-term effects of perinatal asphyxia on monoamine, amino acid and glycolysis product levels measured in the basal ganglia of the rat. Dev Brain Res 104:19-30

12. Dell'Anna E, Chen Y, Loidl F, Andersson K, Luthman J, Goiny M, Rawal R, Lindgren T, Hererra-Marschitz M 1995 Short-term effects of perinatal asphyxia studied with Fos-immunocytochemistry and in vivo microdialysis in the rat. Exp Neurol 131:279-287

13. El-Khodor BF, Boksa P 1997 Long-term reciprocal changes in dopamine levels in prefrontal cortex versus nucleus accumbens in rats born by caesarean section compared to vaginal birth. Exp Neurol 145:118-129

14. Loidl CF, Herrera-Marschitz M, Andersson K, You Z-B, Goiny M, O'Connor WT, Silveira R, Rawal R, Bjelke B, Chen Y, Ungerstedt U 1994 Long-term effects of perinatal asphyxia on basal ganglia neurotransmitter systems studied with microdialysis in rat. Neurosci Lett 175:9-12

15. Chen Y, Hillefors-Berglund M, Herrera-Marschitz M, Bjelke B, Gross J, Andersson K, von Euler G 1997 Perinatal asphyxia induces long-term changes in dopamine D1, D2, and D3 receptor binding in the rat brain. Exp Neurol 146:74-80

16. Boksa P, Krishnamurthy A, Brooks W 1995 Effects of a period of asphyxia during birth on spatial learning in the rat. Pediatr Res 37:489-496

17. El-Khodor BF, Boksa P 1998 Birth insult increases amphetamine-induced behavioral responses in the adult rat. Neuroscience 87:893-904

18. Ungethüm U, Chen Y, Gross J, Bjelke B, Bolme P, Eneroth P, Heldt J, Loidl CF, Herrera-Marschitz M, Andersson K 1996 Effects of perinatal asphyxia on the mesostriatal/mesolimbic dopamine system of neonatal and 4-week-old male rats. Exp Brain Res 112:403-410

19. Delivoria-Papadopoulos M, Mishra OP 1998 Mechanisms of cerebral injury in perinatal asphyxia and strategies for prevention. J Pediatr 132:S30-S34

20. Barks JDE, Silverstein FS 1992 Excitatory amino acids contribute to the pathogenesis of perinatal hypoxic-ischemic brain injury. Brain Pathol 2:235-243

21. Kohlhauser C, Kaehler S, Mosgoeller W, Singewald N, Kouvelas D, Prast H, Hoeger H, Lubec B 1999 Histological changes and neurotransmitter levels three months following perinatal asphyxia in the rat. Life Sci 64:2109-2124

22. Hollmann M, Heinemann S 1994 Cloned glutamate receptors. Ann Rev Neurosci 17:31-108

23. Kessler M, Terramani T, Lynch G, Baudry M 1989 A glycine site associated with N-methyl-D-aspartic acid receptors: characterization and identification of a new class of antagonists. J Neurochem 52:1319-1328

24. Eastman CL, Guilarte TR 1989 The role of hydrogen peroxide in the in vitro cytotoxicity of 3-hydroxykynurenine. Neurochem Res 15:1101-1107

25. Okuda S, Nishiyama N, Saito H, Katsuki H 1996 Hydrogen peroxide-mediated neuronal cell death induced by an endogenous neurotoxin, 3-hydroxykynurenine. Proc Natl Acad Sci U S A 93:12553-12558

26. Guidetti P, Schwarcz R 1999 3-Hydroxykynurenine potentiates quinolinate but not NMDA toxicity in the rat striatum. Eur J Neurosci 11:3857-3863

27. Andiné P, Lehmann A, Ellren K, Wennberg E, Kjellmer I, Nielsen T, Hagberg H 1988 The excitatory amino acid antagonist kynurenic acid administered after hypoxicischemia in neonatal rats offers neuroprotection. Neurosci Lett 90:208-212

28. Nozaki K, Beal MF 1992 Neuroprotective effects of L-kynurenine on hypoxiaischemia and NMDA lesions in neonatal rats. J Cereb Blood Flow Metab 12:400-407

29. Beal MF, Swartz KJ, Isacson O 1992 Developmental changes in brain kynurenic acid concentrations. Dev Brain Res 68:136-139

30. Walker DW, Curtis B, Lacey B, Nitsos I 1999 Kynurenic acid in brain and cerebrospinal fluid of fetal, newborn, and adult sheep and effects of placental embolization. Pediatr Res 45:820-826

31. Ceresoli-Borroni G, Schwarcz R 1997 Kynurenines in the prenatal and early postnatal rat brain. Abstr Soc Neurosci 23:9035
32. Swartz KJ, Matson WR, MacGarvey U, Ryan EA, Beal MF 1990 Measurement of kynurenic acid in mammalian brain extracts and cerebrospinal fluid by highperformance liquid chromatography with fluorometric and coulometric electrode array detection. Anal Biochem 185:363-376

33. Heyes MP 1988 Quantification of 3-hydroxykynurenine in brain by high-performance liquid chromatography and electrochemical detection. J Chromatogr 428:340-344

34. Lowry OH, Rosebrough NJ, Farr AL, Randall RJ 1951 Protein measurement with Folin phenol reagent. J Biol Chem 193:265-275

35. Guidetti P, Eastman CL, Schwarcz R 1995 Metabolism of $5-{ }^{3} \mathrm{H}-\mathrm{kynurenine}$ in the rat brain in vivo: evidence for the existence of a functional kynurenine pathway. J Neurochem 15:2621-2632

36. Heyes MP, Saito K, Crowley J, Davis LE, Demitrak MA, Der M, Dilling L, Kruesi MJP, Lackner A, Larson SA, Lee K, Leonard H, Markey SP, Martin A, Milstien S, Mouradian MM, Pranzatelli MR, Quearry BJ, Salazar A, Smith M, Straus SE, Sunderland T, Swedo S, Tourtellotte WW 1992 Quinolinic acid and kynurenine pathway metabolism in inflammatory and non-inflammatory neurologic disease. Brain 115:1249-1273

37. Saito K, Markey SP, Heyes MP 1992 Effects of immune activation on quinolinic acid and neuroactive kynurenines in the mouse. Neuroscience 51:25-39

38. Du F, Schmidt W, Okuno E, Kido R, Köhler C, Schwarcz R 1992 Localization of kynurenine aminotransferase immunoreactivity in the rat hippocampus. J Comp Neurol 321:477-487

39. Ceresoli-Borroni G, Guidetti P, Schwarcz R 1999 Acute and chronic changes in kynurenate formation following an intrastriatal quinolinate injection in rats. J Neural Transm 106:229-242

40. Schwarcz R, Guidetti P, Roberts RC 1996 Quinolinic acid and kynurenic acid: glia-derived modulators of excitotoxic brain injury. In: Aschner M, Kimelberg HK (eds) The Role of Glia in Neurotoxicity. CRC Press, Boca Raton, FL, pp 245-262

41. Ceresoli-Borroni G, Dong HX, Arends JJA, Fazzaro A, Ma DD, He YY, Hsu CY, Schwarcz R, Jacquin MF 1998 Increased levels of 3-hydroxykynurenine (3-HK) after spinal contusion injury in rats. Abstr Soc Neurosci 24:2908

42. Ceresoli G, Guidetti P, Schwarcz R 1997 Metabolism of $\left[5-{ }^{3} \mathrm{H}\right]-$ kynurenine in the developing rat brain in vivo: effect of intrastriatal ibotenate injections. Dev Brain Res 100:73-81

43. Baran H, Gramer M, Hönack D, Löscher W 1995 Systemic administration of kainate induces marked increases of endogenous kynurenic acid in various brain regions and plasma of rats. Eur J Pharmacol 286:167-175

44. Wu H-Q, Schwarcz R 1996 Seizure activity causes elevation of endogenous extracellular kynurenic acid in the rat brain. Brain Res Bull 39:155-162

45. Schwarcz R, Meldrum B 1985 Excitatory amino acid antagonists provide a novel therapeutic approach to neurological disorders. Lancet 2:140-143

46. Malenka RC, Nicoll RA 1999 Long-term potentiation — a decade of progress? Science 285:1870-1874

47. Scheetz AJ, Constantine-Paton M 1994 Modulation of NMDA receptor function: implications for vertebrate neural development. FASEB J 8:745-752

48. Komuro H, Rakic P 1993 Modulation of neuronal migration by NMDA receptors. Science 260:95-97

49. Poeggeler B, Rassoulpour A, Guidetti P, Wu H-Q, Schwarcz R 1998 Dopaminergic control of kynurenate levels and NMDA toxicity in the developing rat striatum. Dev Neurosci 20:146-163

50. Harris CA, Miranda AF, Tanguay JJ, Boegman RJ, Beninger RJ, Jhamandas K 1998 Modulation of striatal quinolinate neurotoxicity by elevation of endogenous brain kynurenic acid. Brit J Pharmacol 124:391-399

51. Cozzi A, Carpenedo R, Moroni F 1999 Kynurenine hydroxylase inhibitors reduce ischemic brain damage: studies with (m-nitrobenzoyl)-alanine (mNBA) and 3,4dimethoxy-[-N-4-(nitrophenyl)thiazol-2-yl]-benzenesulfonamide (Ro 61-8048) in models of focal or global brain ischemia. J Cereb Blood Flow Metab 19:771-777

52. Wu H-Q, Guidetti P, Goodman JH, Varasi M, Ceresoli-Borroni G, Speciale C, Scharfman HE, Schwarcz R 2000 Kynurenergic manipulations influence excitatory synaptic function and excitotoxic vulnerability in the rat hippocampus in vivo. Neuroscience 97:243-251

53. Schurr A, Payne RS, Miller JJ, Rigor BM 1997 Brain lactate, not glucose, fuels the recovery of synaptic function from hypoxia upon reoxygenation: an in vitro study. Brain Res 744:105-111

54. Ceresoli-Borroni G, O’Brien J, McKenna MC, Schwarcz R 2000 Acute and subacute effects of neonatal asphyxia on the levels of kynurenine pathway and energy metabolites in the rat brain. Abstr Soc Neurosci 26:324

55. Poon C-S, Zhou Z, Champagnat J 2000 NMDA receptor activity in utero averts respiratory depression and anomalous long-term depression in newborn mice. J Neurosci $20:$ RC73 